\title{
Restricted feeding and incidence of activity-stress ulcers in the rat
}

\author{
WILLIAM P. PARÉ, GEORGE P. VINCENT, KILE E. ISOM, and JESSE M. REEVES \\ Pavlovian Research Laboratory, Veterans Administration Hospital, Perry Point, Maryland 21902
}

\begin{abstract}
Rats housed in running-wheel activity cages and fed $1 \mathrm{~h}$ daily exhibited excessive running and subsequently died revealing large stomach ulcers. However, prior experience with a 1-h feeding schedule for 15 days before exposure to the activity-stress procedure did significantly extend survival time. A second study illustrated that feeding schedules of $.5,1.0,1.5$, or $2.0 \mathrm{~h}$ daily did not yield differences in terms of stomach ulcers or survival time, but a 3-h daily feeding did significantly reduce ulcer incidence and increase survival time.
\end{abstract}

The standard activity-stress ulcer procedure involves placing young adult rats in running-wheel activity cages for a 4-day habituation period and subsequently feeding these animals $1 \mathrm{~h}$ each day. This procedure invariably leads to excessive running activity and after 3 or 4 days, these rats die and reveal large hemorrhagic ulcers in the glandular stomach. Pair-fed control rats, which do not have access to a running wheel, do not die and are ulcer free (Barboriak \& Knoblock, 1972; Paré, 1975; Paré \& Houser, 1973). The two variables of running activity and restricted feeding are etiologically related to activity-stress ulcer, but their relative contribution to ulcer development is unknown. To date, the majority of research reports on activity-stress ulcers have utilized a 1-h restricted feeding period. The relationship between extended feeding periods and ulcer incidence is unknown. Also, habituation to a 1 -h feeding period may possibly ameliorate the ulcerogenic process. This report represents an attempt to address these questions and to clarify the role of restricted feeding on activity-stress ulcer development.

\section{EXPERIMENT 1}

In his early work on restricted feeding of rats in activity wheels, Routtenberg (1968) suggested that the depression of daily feeding may be partly due to the stress of being housed in a novel environment (i.e., the activity-wheel cage). The novel activity wheel may initiate affective states that inhibit consummatory behavior. In a similar fashion, the 1-h feeding schedule is a novel schedule for the rat, and while the animal is adapting to this schedule, the animal may not exhibit optimal consummatory behavior. Yager, Lichtenstein, Bonney, Hopkins, Walker, Dorn, and Potter (1974) suggested that rats can be adapted to a restricted feeding

This research was supported by Veterans Administration Medical Research Project BEHS 29. The authors wish to thank Luther R. Gilliam of the Veterans Administration Medical Media Service, Perry Point, Maryland, for the illustrations. schedule in order to survive subsequent 40 -h deprivation experiences. Leveille and O'Hea (1967) reported that rats pretrained to a 2 -h feeding schedule exhibited lower spontaneous activity and gained more weight than control rats. These studies suggest that the deprivation history may have important consequences on the rat's ability to survive when exposed to the activity-stress procedure. The hypothesis tested was that rats having prior experience with a 1 -h feeding schedule would survive longer when subsequently subjected to the activity-stress procedure.

\section{Method}

Animals and Apparatus. Twenty-four male Sprague-Dawley rats (250-288 g) were used. The apparatus consisted of standard running-wheel activity cages (Wahmann Manufacturing Company, Baltimore, Maryland). Each activity wheel was equipped with an adjoining cage measuring $24 \times 15 \times 13 \mathrm{~cm}$. A sliding door separated the cage from its adjoining wheel. A wheel revolution was recorded for each activity cage by digital counters. Room temperature was controlled between $23^{\circ} \mathrm{C}$ and $24^{\circ} \mathrm{C}$ and daylight conditions were simulated between $6: 00$ am and 6:00 pm.

Procedure. Rats were equated on the basis of body weight into two treatment groups. The two groups were a 1-h feedinghabituation group $(n=12)$ and a control group $(n=12)$. All experimental and control rats were individually housed in activity-wheel running cages for a 15-day habituation period. During this period the door separating the living cages from the running wheel was closed, thereby preventing access to the wheel. Food and water were continuously available to rats in the control group. Rats in the 1-h feeding-habituation group were fed for only $1 \mathrm{~h}$ between 9:00 am and 10:00 am. After the 15-day habituation period, food was removed from all rats at 10:00 am, and the door separating the cages from the wheel was opened. On the next day, and on subsequent days, control rats as well as experimental rats were fed for $1 \mathrm{~h}$ between 9:00 am and 10:00 am. Body weight, wheel revolutions, and food consumption were recorded daily. Stomachs were removed immediately from rats that died, and these were inspected for lesions. After 18 days of restricted feeding for both groups, the experiment was terminated and all surviving rats were killed and their stomachs inspected for lesions.

\section{Results}

There were no significant differences in daily running 


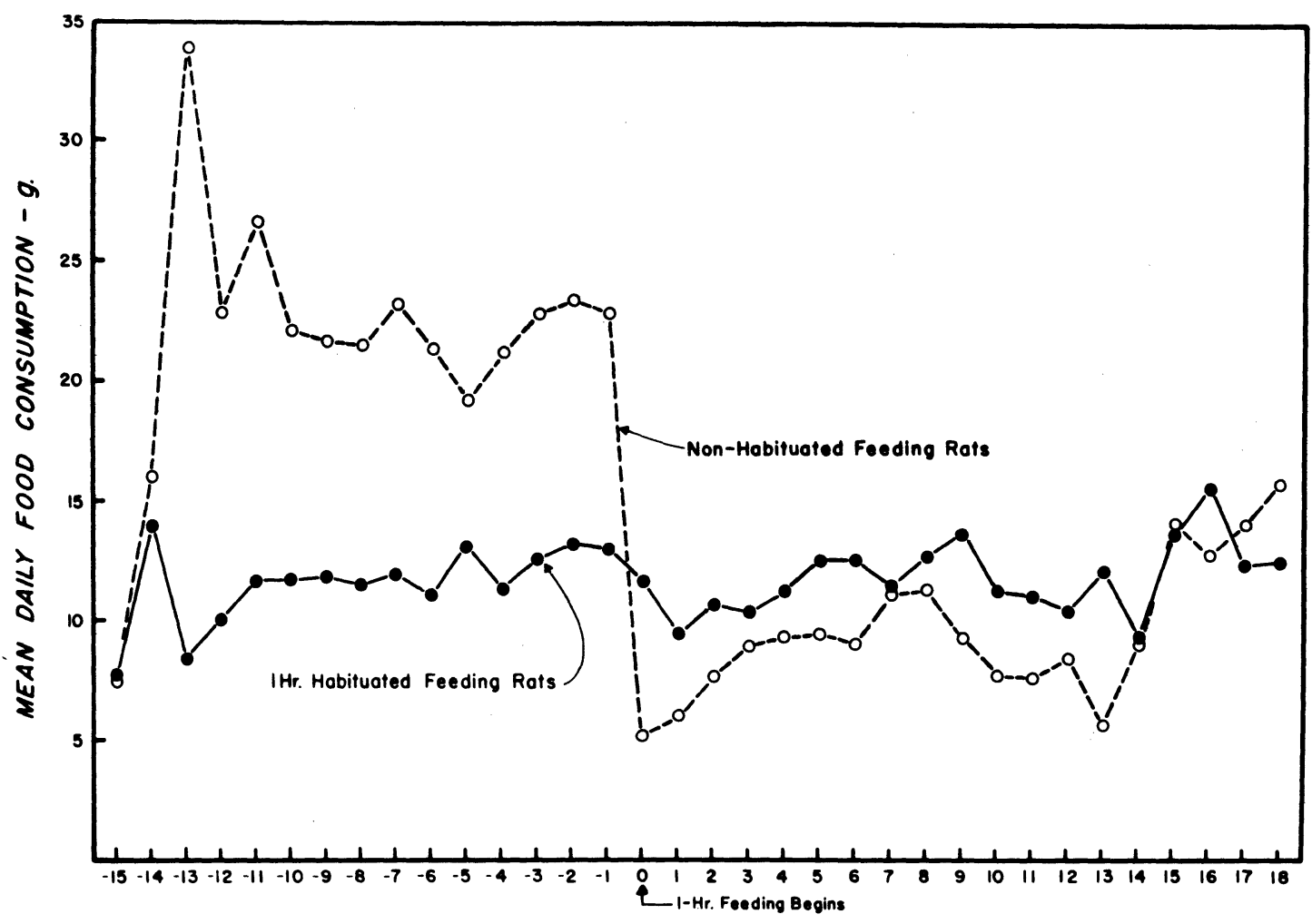

DAYS

Figure 1. Mean daily food consumption for rats habituated to the 1-h feeding schedule and control rats fed ad lib during the habituation period and $1 \mathrm{~h}$ during the activity-stress period.

activity between experimental and control rats. An analysis of the 1-h food-consumption data for the first 6 days when both treatment groups were on the restricted feeding schedule revealed that the rats fed on a 1-h basis during the habituation period ate more food on subsequent days when both groups were on the restricted feeding schedule $[F(1,22)=17.38, \mathrm{p}<.01]$. Thus, experimental rats were more efficient and optimized the 1-h feeding period by consuming more food. These results are illustrated in Figure 1. These rats also survived longer as compared to control rats $[\mathrm{t}(22)=2.87, \mathrm{p}<.01]$ but, as Table 1 indicates, the number of lesions or the length of lesions did not differ significantly between groups.

This study demonstrated that the animal's deprivation history can influence survival time. Previous experience with a $1 \cdot h$ feeding schedule thus mitigates the effects of the activity-stress procedure.

\section{EXPERIMENT 2}

Experiment 1 demonstrated that as animals consume more food during the feeding period, survival time in the activity-stress procedure increases. The animal can increase its total food intake during the feeding period by either being more efficient (i.e., increasing consumption/feeding time available) or by having access to a longer feeding period. Experiment 1 essentially trained rats to be efficient consumers during the 1-h feeding period. Experiment 2 investigated whether rats with 2- or 3-h feeding periods, and consequently the opportunity to consume more food, would still develop activity-stress ulcers.

\section{Method}

Animals and Apparatus. Sixty male Sprague-Dawley rats $(201-230 \mathrm{~g})$ were used in this study. The same running-wheel activity cages described in Experiment 1 were used in this experiment.

Table 1

Summary (Mean and Standard Error) of Survival Time and Stomach Condition for Experiment 1

\begin{tabular}{lrrrrrr}
\hline & \multicolumn{4}{c}{$\begin{array}{c}\text { Habituation Treatment } \\
\text { Condition }\end{array}$} \\
\cline { 2 - 5 } & 1-h Feeding & & 24-h Feeding \\
\cline { 2 - 5 } \cline { 2 - 5 } & M & SE & M & SE & t Test \\
\hline Days of Lesions & 16.2 & .93 & 11.6 & 1.28 & $2.87^{*}$ \\
Number of Lesions & 13.0 & 4.18 & 20.1 & 3.88 & 1.24 \\
Length of Lesions (mm) & 35.5 & 11.15 & 49.1 & 8.65 & .95 \\
\hline
\end{tabular}

Note $-N=12$ for both conditions. Number of rats with lesions in the 1-h feeding condition $=7$, in the 24-h feeding condition $=10$. ${ }^{*} p<.01$ 
Procedure. Rats were separated into five treatment groups. The groups were equated for body weight. All rats were individually housed in activity-wheel cages for a 4-day habituation period. During this period, food and water were always available and rats also had continuous access to the running wheel. On Day 5, food was removed at 9:00 am. On Day 6, the restricted feeding schedule started. Groups 1-5 were fed for periods of $.5,1.0,1.5,2.0$, and $3.0 \mathrm{~h}$, respectively. Daily feedings started at 9:00 am and were terminated according to the length of the assigned feeding period. Therefore, Group 1 rats, with a .5-h schedule, were fed between 9:00 am and 9:30 am; Group 2 rats, with a 1-h schedule, were fed between 9:00 am and 10:00 am, and so on. Body weight, food consumption, and running activity were recorded daily. When a rat died, the stomach was removed and inspected for lesions. The study continued for 7 days, when all surviving rats were killed and stomachs were inspected.

\section{Results}

The various feeding schedules resulted in differences in food consumed $[F(4,55)=18.72, p<.01]$, but only the animals on the 3-h schedule differed significantly from the other groups (Tukey a test, $\mathrm{p}<.05$ ). There were no significant differences in daily food consumption between rats in the .5-, 1.0-, 1.5-, or 2.0-h groups. Only when rats had access to a $3-\mathrm{h}$ feeding interval did food consumption increase significantly. These data are illustrated in Figure 2. An analysis of daily running activity for the first 3 days produced similar significant differences $[F(4,55)=4.52, p<.01]$, with rats on the $3-\mathrm{h}$ feeding schedule running significantly less (Tukey a test, $p<.05$ ) and no significant differences emerging between the other four treatment groups. These group differences were also reflected in the ulcer-incidence data (see Table 2). Only two rats in the 3-h feeding group had stomach ulcers, whereas all the rats in the other four groups had ulcers. Rats in the 3-h feeding group also survived longer than all the other groups combined.

Feeding rats for time periods ranging from .5 to $2.0 \mathrm{~h}$ has essentially the same effect in terms of daily food consumption, ulcer incidence, and survival time. Extending the feeding period to $3 \mathrm{~h}$ significantly mitigates the effects of the activity-stress procedure.

\section{DISCUSSION}

The mean number of survival days for experimental rats in Experiment 1 was greater than the mean number of survival

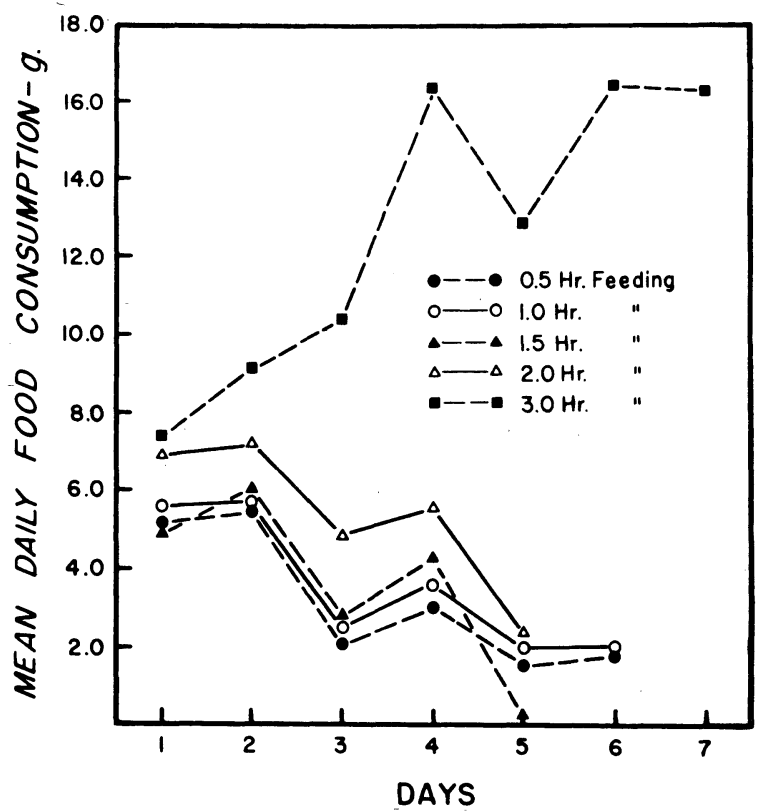

Figure 2. Mean daily food consumption for treatment groups fed for $.5,1.0,1.5,2.0$, or $3.0 \mathrm{~h}$ during the activity-stress period.

days for rats in Experiment 2. However, rats in Experiment 1 were heavier, averaging approximately $58 \mathrm{~g}$ more than rats in Experiment 2, and heavier rats survive longer in the activitystress situation partly because they are less active (Paré , 1975).

These two studies illustrate that susceptibility to activitystress ulcer can be influenced by manipulating feeding parameters. Experience with a 1-h feeding period resulted in greater food consumption, as compared to controls, once animals had access to the running wheel. Extending the feeding period to $3 \mathrm{~h}$ also reduced ulcer incidence. These results suggest that reduced feeding plays a critical role in the development of the ulcers. As such, these data are consistent with reports of other ulcerogenic techniques. Except for the supine restraint technique (Vincent, Glavin, Rutkowski, \& Paré, 1977), all ulcerogenic techniques require that animals be food deprived at least $24 \mathrm{~h}$. Therefore, the empty gut must be an important predisposing condition. However, it is interesting to note in Experiment 2 that rats with $2-h$ daily feeding schedules, and even some animals with 3 -h feeding schedules, developed ulcers. Food consumption for these periods was not sufficient to prevent ulcers. Possibly, the high energy demand characteristics of the activity-stress technique cannot be supported due to restricted feeding schedule, and the resulting metabolic imbalance leads to stress ulcer. These studies do provide information regarding the impact of feeding parameters on activity-

Table 2

Summary (Mean and Standard Error) of Survival Time and Stomach Condition for Experiment 2

\begin{tabular}{|c|c|c|c|c|c|c|c|c|c|c|c|}
\hline & \multicolumn{10}{|c|}{ Length of Daily Feeding Period } & \multirow[b]{3}{*}{$\mathrm{F}$} \\
\hline & \multicolumn{2}{|c|}{$.5 \mathrm{~h}$} & \multicolumn{2}{|c|}{$1.0 \mathrm{~h}$} & \multicolumn{2}{|c|}{$1.5 \mathrm{~h}$} & \multicolumn{2}{|c|}{$2.0 \mathrm{~h}$} & \multicolumn{2}{|c|}{$3.0 \mathrm{~h}$} & \\
\hline & $\mathbf{M}$ & SE & $\mathbf{M}$ & SE & $\mathbf{M}$ & SE & $\mathbf{M}$ & SE & $\mathbf{M}$ & SE & \\
\hline $\begin{array}{l}\text { Days Survived } \\
\text { Number of Lesions } \\
\text { Length of Lesions }(\mathrm{mm})\end{array}$ & $\begin{array}{r}3.0 \\
23.6 \\
61.9 \\
\end{array}$ & $\begin{array}{r}.31 \\
1.93 \\
5.05 \\
\end{array}$ & $\begin{array}{r}3.3 \\
22.0 \\
82.0 \\
\end{array}$ & $\begin{array}{r}.25 \\
2.43 \\
6.20 \\
\end{array}$ & $\begin{array}{r}3.2 \\
25.6 \\
73.4 \\
\end{array}$ & $\begin{array}{r}.11 \\
2.74 \\
7.37 \\
\end{array}$ & $\begin{array}{r}3.4 \\
22.0 \\
50.1 \\
\end{array}$ & $\begin{array}{r}.22 \\
3.68 \\
5.38 \\
\end{array}$ & $\begin{array}{l}6.5 \\
4.5 \\
9.3 \\
\end{array}$ & $\begin{array}{r}.35 \\
3.11 \\
6.18 \\
\end{array}$ & $\begin{array}{r}29.56^{*} \\
8.20^{*} \\
21.11^{*} \\
\end{array}$ \\
\hline
\end{tabular}

Note $-N=12$ for all groups. Number of rats with lesions in the 3-h group = 2; in all other groups, number of rats with lesions $=12$. ${ }^{*} p<.01$ 
stress ulcer formation but also indicate that these variables may be ulcerogenic only to the extent that they interact with the activity variable.

\section{REFERENCES}

Barboriak, J. J., \& KNOBLOCK, H. W., JR. Gastric lesions in food-restricted young rats. Proceedings of the Society of Experimental Biology and Medicine, 1972, 141, 830-832.

LEVEILle, G. A., \& O'HEA, E. K. Influence of periodicity of eating on energy metabolism in the rat. Journal of Nutrition, 1967, 93, 541-545.

PARÉ, W. P. The influence of food consumption and running activity on the activity-stress ulcer in the rat. American Journal of Digestive Diseases, 1975, 20, 262-273.
Paré, W. P., \& Houser, V. P. Activity and food-restriction effects on gastric glandular lesions in the rat: The activity-stress ulcer. Bulletin of the Psychonomic Society, 1973, 2, 213-214.

ROUTTENBERG, A. "Self-starvation" of rats living in activity wheels: Adaptation effects. Journal of Comparative and Physiological Psychology, 1968, 66, 234-238.

Vincent, G., Glavin, G., Rutkowski, J., \& Paré, W. Body orientation, food deprivation and potentiation of restraint induced gastric lesions. Gastroenterologie Clinique et Biologique, 1977, 1, 539-543.

YAGeR, J. D., Lichtenstein, M. J., Bonney, R. J., Hopkins, H. A., W Alker, R. P., Dorn, G. C., \& Potter, V. R. Effects of various feeding and exercise regimens on rat growth and survival. Journal of Nutrition, 1974, 104, 273-286.

(Received for publication May 5, 1978.) 